\title{
UMA PROPOSTA DE OBJETO DE APRENDIZAGEM UTILIZANDO A TEORIA DAS INTELIGÊNCIAS MÚLTIPLAS
}

\author{
Fátima Weber Rosas - UFRGS/NUTED - fatima@ caef.ufrgs.br \\ Letícia Rocha Machado - UFRGS/NUTED - leticiarmachado@yahoo.com.br \\ Rissem Hwas - UFRGS - rissemhwas@yahoo.com.br \\ Terezinha Torres - UFRGS - terezinha.torres@metodistadosul.edu.br \\ Patricia Alejandra Behar - UFRGS/NUTED - patricia.behar@ufrgs.br
}

Resumo: Este artigo trata do desenvolvimento de um objeto de aprendizagem (OA) baseado na Teoria das Inteligências Múltiplas de Gardner. $\mathrm{O}$ autor defende a idéia de que cada sujeito possui potenciais que interferem na aprendizagem podendo ou não ser intensificados, onde cabe ao educador motivar estes potenciais. Com base nas perspectivas e possibilidades que a teoria oportuniza, foi construído um objeto de aprendizagem (OA) denominado IM (Inteligências Múltiplas). Este objeto foi pensado e desenvolvido para ser utilizado tanto de forma semi-presencial como virtual, com o objetivo de auxiliar o educador na sua prática docente.

Palavras chave: Inteligências Múltiplas - Virtualidade - Habilidades - Objeto de Aprendizagem.

\section{A PROPOSAL FOR PURPOSE OF LEARNING USING THE THEORY OF MULTIPLE INTELLIGENCE}

\begin{abstract}
This article deals with the development of a learning object (OA) based on the Theory of Multiple Intelligences of Gardner. The author defends the idea that each individual possesses potentials that interfere in the learning being able or not of to be intensified, being educator's responsibility to stimulate these potentials. With base in the perspectives and possibilities that the theory can proportionate, a learning object was built (OA) denominated IM (Multiple Intelligences). This object was thought and built for so much to be used blended learning as virtually, with the objective to assist the educator in the application your contents.
\end{abstract}

Keywords: Multiple Intelligences - Virtually - Abilities - Learning Objects.

\section{INTRODUÇÃO}

O presente artigo apresenta o Objeto de Aprendizagem (OA) Inteligências Múltiplas (IM) o qual se encontra disponível em: http://homer.nuted.edu.ufrgs.br/oficinas_2009/objetos/FLASH_PIM-index/index.html. Este OA foi construído para possibilitar o desenvolvimento/aprimoramento das inteligências múltiplas nas práticas pedagógicas à distância, semi-presenciais ou presenciais, bem como proporcionar um maior aprofundamento sobre a teoria para educadores que pretendem estimular as inteligências de seus educandos.

O OA IM surgiu da necessidade do educador utilizar-se das vantagens que os avanços tecnológicos proporcionam, questionando: Como trabalhar com um público heterogêneo virtualmente? Como dar suporte de qualidade no virtual? A partir destes questionamentos começou-se a pensar num tema para a construção de um objeto de aprendizagem. O presente objeto foi construído durante a disciplina, Oficinas Virtuais de Aprendizagem ${ }^{l}$, como tarefa final que deveria ser em grupo. Devido a cada uma das quatro componentes do grupo, ou seja, das autoras ${ }^{2}$ do OA pertencerem a quatro 
diferentes áreas do conhecimento, houve uma dificuldade de escolher um tema para o mesmo. Diante deste impasse, a professora sugeriu a Teoria das Inteligências Múltiplas de Gardner. Foi aí que o OA IM começou. Desta maneira, o OA IM, cuja essência está na interdisciplinaridade, permitiu a interação das diversas áreas do conhecimento através da integração das diversas inteligências, permitindo a contribuição de todas as autoras com seus conhecimentos específicos, de forma que nenhuma área do conhecimento fosse minimizada.

O OA IM tem por objetivo facilitar o processo de aprendizagem de maneira multi e interdisciplinar, utilizando diversos materiais educacionais digitais como vídeos, arquivos áudio, animações, textos, hipertextos, imagens. O OA IM também pretende oferecer fundamentos iniciais sobre as inteligências múltiplas, reconhecendo a importância destas na educação. O objeto é voltado para educadores que desejam conhecer/aperfeiçoar sobre a teoria das inteligências múltiplas, bem como a sua aplicação no virtual ou presencial, sendo os estimuladores do processo de aprendizagem. O OA IM busca valorizar as competências e habilidades do educador que o utilizar e ao mesmo tempo estimular as habilidades no educando.

\section{INTELIGÊNCIAS MÚLTIPLAS: UM POUCO MAIS SOBRE A TEORIA}

Apesar de muitas discussões envolvendo o tema, Gardner defende que existem diversas competências intelectuais humanas que inicialmente foram categorizadas em seis inteligências. Mais tarde foram acrescentadas mais três inteligências. Neste objeto optou-se pelas seis primeiras, por serem mais apropriadas à virtualidade: Inteligência Lingüística, Lógico-Matemática, Espacial, Musical, Corporal Cinestésica e Inteligências Pessoais. Segundo o autor, as inteligências, são relativamente independentes umas das outras, mas podem (e devem) ser combinadas em uma multiplicidade de possibilidades de maneiras adaptativas por indivíduos e culturas. Como cita Gardner (2002, p.7) "[...] estas inteligências trabalham em harmonia, então sua autonomia pode ser invisível".

A teoria das Inteligências Múltiplas começou a ser estuda por autores que questionavam os testes de QI, tendo destaque Howard Gardner que propôs uma nova concepção do que seria a inteligência. Gardner (2002) discute o valor que os testes de inteligência, ou teste de Quociente de Inteligência (QI) possuíam. Acreditando que o sucesso escolar não se devia apenas ao QI, Gardner redefine inteligência à luz das origens biológicas e da habilidade para resolver problemas. A partir daí, inteligências que antes não eram valorizadas como a musical, a cinestésica ou ainda as pessoais, passam a ser tão consideradas quanto a Inteligência lógico-matemática ou a Inteligência Linguística. Conforme Gardner (2002, p.04) "Apenas quando expandirmos e reformularmos nossa concepção do que conta como intelecto humano seremos capazes de projetar meios mais adequados para avaliá-lo e meios mais eficazes para educá-lo".

De acordo com o autor, o desenvolvimento de cada Inteligência está baseado num potencial biológico e nos resultados da interação dos fatores genéticos com o meio. Todas as inteligências devem ser estimuladas através de atividades diversas em todos os indivíduos desde a mais tenra idade, pois nem todos aprendem do mesmo modo. Todos os indivíduos apresentam uma mistura de várias inteligências, onde algumas podem ser mais desenvolvidas que outras. (Rocha e Barone 2001).

$\mathrm{O}$ autor ainda menciona que poderia haver até trezentos outros tipos de inteligências. A seguir, as nove inteligências mais difundidas nos dias de hoje:

-Inteligência Existencial: O ser como pessoa integral. Uma visão que, de certa forma, abrange, de maneira contingencial, as demais inteligências, bem como todo contingencial existencial; 
-Inteligência Naturalista: O indivíduo que revela maior inclinação pelos fenômenos da natureza, demonstrando grande experiência no reconhecimento e classificação de variadas espécies, tanto da fauna como da flora;

-Inteligência Espiritual: É uma inteligência que explora a natureza da existência em suas múltiplas formas nossa existência como indivíduos no cosmos e à nossa capacidade de nos estarrecermos diante de tal fato. Esta inteligência, segundo Gardner (2000) ainda deve ser estudada e discutida;

-Inteligência Lingüística: Refere-se às pessoas voltadas para a fala, para a escrita. A linguagem está ligada à capacidade de recordar. Desde os primórdios, oradores, poetas, filósofos e todos dependem da linguagem tanto em sua forma oral quanto na escrita. Sendo que na escrita, o indivíduo precisa de habilidades adicionais, pois deve apenas com palavras, apresentar seu assunto, enquanto que na oral, pode valer-se de gestos e entonações, assim como na língua de sinais;

-Inteligência Lógico-Matemática: Trata das pessoas que possuem facilidade em lidar com os números e raciocínio lógico e é apoiada por critérios empíricos. Essa inteligência determina interpretação de cálculos e na percepção dos espaços e figuras geométricos, na capacidade de abstrair situações lógicas e problemáticas;

-Inteligência Espacial: Diz respeito a quem tem facilidade em se colocar e se deslocar no espaço que nos envolve possibilitando que administremos e percebemos distâncias e pontos de referências, em imaginar, desconstruir imagens. Podem operar como uma "família", e o uso de uma poderá reforçar o uso das outras;

-Inteligência Corporal-Cinestésica: Está ligada à coordenação motora, aos sentidos, à expressão corporal. Segundo Gardner: "[...] A inteligência corporalcinestésica envolve o uso de todo o corpo ou de partes do corpo para resolver problemas ou criar produtos" Gardner (et al, 1998, p.221). De acordo com o mesmo autor (1995) os aspectos cognitivos do uso do corpo evidenciam-se na capacidade de utilizá-lo para expressar emoções, como na dança, jogar um jogo ou criar um novo produto (como no planejamento de uma invenção). As principais características desta inteligência são o controle dos movimentos do próprio corpo e a capacidade de manusear objetos com habilidade. Costa et al (2001) afirma que indivíduos que possuem a capacidade de manipular objetos com refinamento, como artesãos e instrumentistas, são exemplos de indivíduos que possuem elevada Inteligência Corporal-Cinestésica.

-Inteligência Musical: Refere-se a pessoas que utilizam da habilidade musical em seu aproveito, como forma de aprimoramento. De acordo com Gardner et al (1998 apud Rocha et al, 2001, p.47): "Inteligência Musical é a capacidade de interpretar, escrever, ler e expressar-se pela música". "A Inteligência musical também consiste na sensibilidade para ritmos e batidas e para o manuseio de instrumentos musicais". Barone, \& Silveira (2001, p.17). Estudos e testes realizados comprovam a independência da inteligência musical, justificando sua inclusão entre as demais. Além da herança genética, Gardner (1995) menciona estudos com crianças autistas que conseguiam tocar perfeitamente um instrumento musical, porém não conseguiam falar. Testes comprovam também que certas partes do cérebro desempenham papéis importantes na percepção e produção da música. Embora a capacidade musical não esteja tão claramente localizada como a capacidade linguística, a musical está mais caracteristicamente localizada no hemisfério direito do cérebro.

-Inteligências Pessoais: Diz respeito ao indivíduo voltado para si mesmo, e sua habilidade para resolver suas questões interiores e capacidade de comunicação. Ele terá de usar a capacidade de observação do mundo e de si mesmo detectando e resolvendo problemas. Ao compreender um problema faz uso da Inteligência Interpessoal. Conquanto use sua sensibilidade e, reflexão das suas observações para entender melhor suas capacidades e a forma de usá-las com a Inteligência Intrapessoal. Para que ele seja 
uma pessoa de pé no chão, um cidadão consciente de sua posição no mundo. A seguir será aprofundado um pouco mais sobre o OA IM, sua estrutura e possível aplicação.

\section{OBJETO DE APRENDIZAGEM IM - INTELIGÊNCIAS MÚLTIPLAS}

De acordo com Behar "Entende-se por objeto de aprendizagem qualquer material digital, como por exemplo, textos, animação, vídeos, imagens, aplicações, páginas web de forma isolada ou em combinação, com fins educacionais" Behar (2009, p.67). A autora também afirma que a utilização de materiais educacionais digitais na forma de OAs tem sido uma boa forma de trabalhar conceitos e conteúdos de maneira dinâmica e interativa nas diversas áreas do conhecimento, possibilitando uma estimulação do aprendiz, tornando-o um sujeito ativo no processo de aprendizagem.

De acordo com Macedo et al (2007) e Wiley (2000) um OA pode ser criado de qualquer mídia ou formato, podendo variar desde uma simples apresentação de slides, até objetos mais sofisticados como simulação. Não existe definido um tamanho para os objetos de aprendizagem, no entanto, ele deve ter uma finalidade educacional com embasamento pedagógico podendo utilizar combinações das diferentes mídias na sua composição, como vídeos, sons/áudios, imagens, textos, animações entre outros. Wiley (2000, p.4-5) também afirma que objeto de aprendizagem é "qualquer entidade, digital ou não digital, que pode ser utilizada, reutilizada ou referenciada durante a aprendizagem apoiada na tecnologia". O autor também escreve que um dos princípios básicos dos OAs é a flexibilidade. Os objetos de aprendizagem devem ser construídos de forma que possibilitem a reutilização em vários contextos de aprendizagem, assim como a atualização caso for necessária Macêdo (et al, 2007; Wiley, 2000).

O objeto de aprendizagem IM foi desenvolvido durante o primeiro Semestre de 2008 na disciplina de Oficinas Virtuais de Aprendizagem do curso de Pós graduação da Informática na Educação e de Educação, da UFRGS para ser aplicado e validado com os alunos da mesma disciplina no primeiro Semestre de 2009. Para a sua construção foram utilizadas as quatro etapas sugeridas por Amante e Morgado (2001): a) Concepção do objeto (o que, para quem e de que forma pretende-se desenvolver o objeto); b) Planificação (colocar em prática todos os pontos planejados durante o desenvolvimento do objeto e a elaboração do storyboard necessária para a fase de implementação); c) Implementação (aplicação do que foi planejado, juntamente com o desenvolvimento propriamente dito); d) Avaliação (aplicação a fim de testar as características técnicas e funcionais, design e didática do produto), sendo que esta última etapa está sendo realizada.

Com o intuito de utilizar recursos multimídias para abordar as inteligências múltiplas, como imagens, vídeos, textos, animações e sons foi utilizado o programa Flash Cs3 a fim englobar a concepção do objeto e sua planificação. Na fase de Planificação foi feito o storyboard (Figura 1) utilizando a ferramenta CmapTools ${ }^{3}$. 


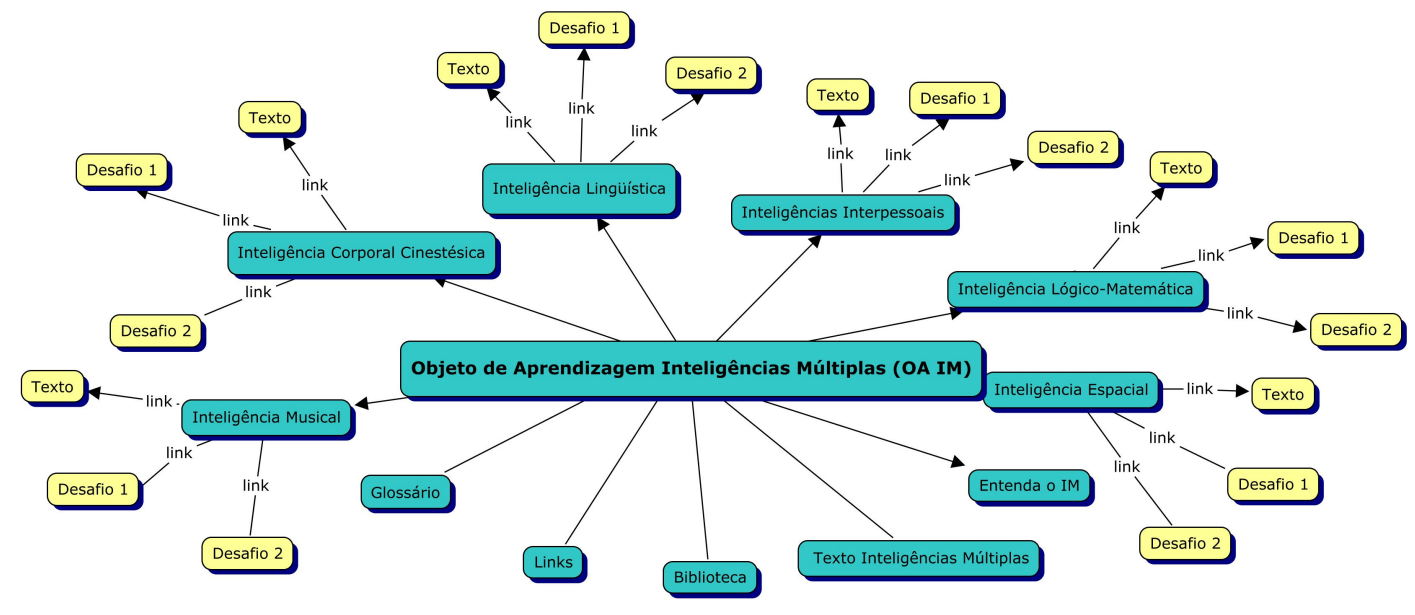

Figura 1 - Storyboard do OA IM

Na tela inicial (Figura 2), foi utilizada a metáfora de uma animação que forma uma teia por se tratar de uma rede de conhecimentos que se integram. Com as lâmpadas, pretende-se dar a conotação de "idéia nova", estas servem como botões de acesso. Cada lâmpada leva a um determinado recurso pedagógico que será explicado a seguir.

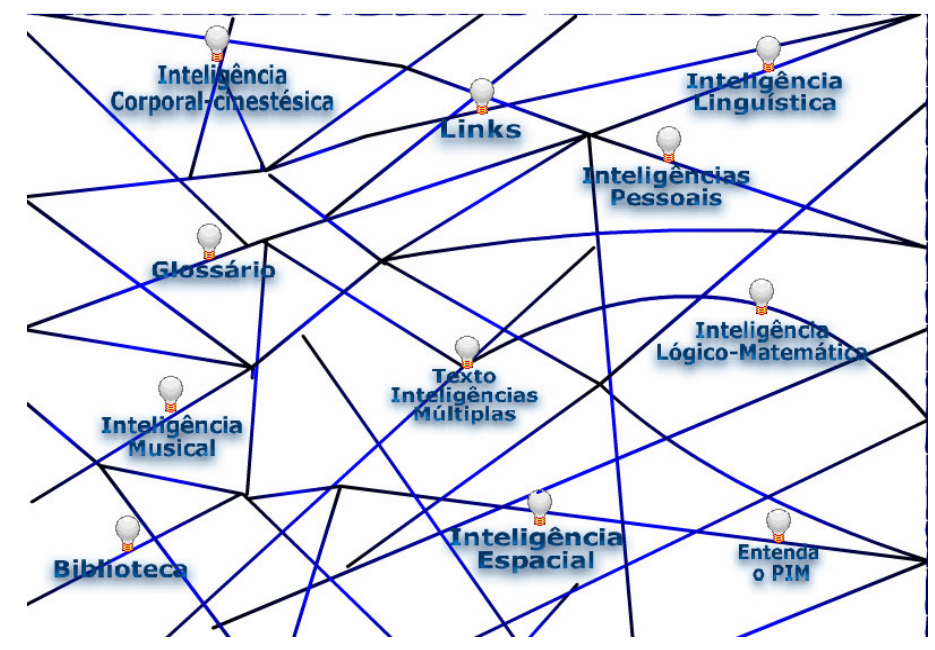

Figura 2 - Tela inicial do OA IM

Os recursos pedagógicos utilizados neste OA foram: "Biblioteca", "Links", "Glossário", "Texto Inteligências Múltiplas", texto "Entendendo o PIM" e cada uma das inteligências trabalhadas: "Inteligência Musical", "Inteligência Espacial", "Inteligência Lógico Matemática", "Inteligência Corporal-Cinestésica", "Inteligência Lingüística", "Inteligências Pessoais" (Inter e Intrapessoal).

O OA IM foi construído de acordo com uma navegação livre, podendo ser sugerido pelo professor uma estratégia de uso conforme sua metodologia. Pelo fato dos recursos pedagógicos disponíveis no objeto serem construídos de forma independente, o usuário poderá utilizá-los de acordo com suas necessidades. Juntamente com o conteúdo explicativo de cada uma das inteligências, existem dois desafios ou atividades cujo objetivo é o de estimular determinada inteligência e ao mesmo tempo o levar a uma 
melhor compreensão da mesma. O aluno ou professor pode optar por utilizar apenas um dos dois desafios para cada inteligência.

$\mathrm{Na}$ "Biblioteca" foi disponibilizado uma lista de livros referentes ao assunto. Já no item "Links", encontra-se sites de vídeos ou artigos relacionados com o tema do objeto (inteligências múltiplas). O "Glossário" foi construído com o intuito de deixar claro termos e conceitos utilizados no decorrer do OA. No recurso "Entenda o IM" encontram-se explicações de como o educador ou educando poderá utilizar da melhor forma o OA IM, bem como as suas funcionalidades e objetivos. No item "Texto sobre Inteligências Múltiplas" foi construído, pelas autoras, um artigo sobre o tema relacionando-o também com questões sobre a virtualidade que será disponibilizado na íntegra para leitura e/ou impressão.

No recurso pedagógico "Inteligência Espacial", assim como nas demais inteligências, foi disponibilizado dois desafios e um texto teórico. No desafio 1 foi disponibilizada uma tela para desenho livre, onde o usuário deve desenhar, sem olhar, o ambiente que se encontra. Pretende-se desenvolver a percepção espacial nestas atividades No desafio 2 (Figura 3) aparece uma figura a qual tem duas interpretações. Esta figura pode ser girada conforme o usuário desejar. Pretende-se ativar as múltiplas percepções humanas desequilibrando conforme o que se tem como padrão.

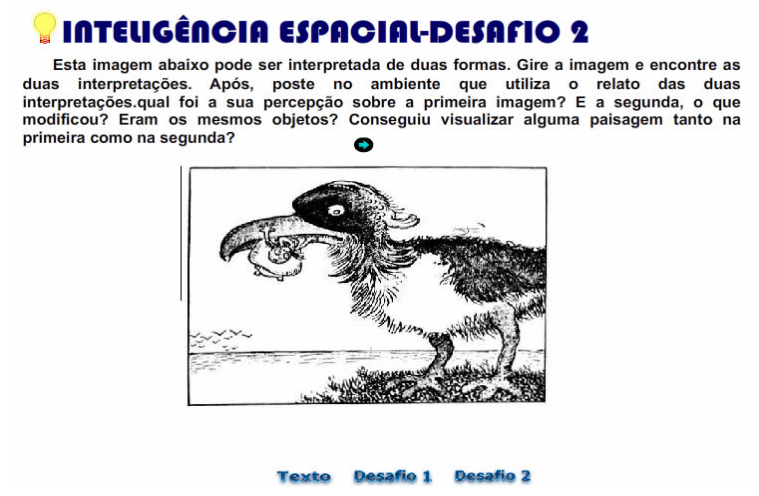

Figura 3 - Desafio 2 da Inteligência Espacial

No recurso pedagógico "Inteligência Musical” também foram apresentados dois desafios. No desafio 1 há um link para realização de um download de um software chamado Mousing. Ao mover o mouse, os parâmetros sonoros intensidade e altura são modificados. Este software também possibilita uma modificação pouco perceptível no timbre. Antes da realização deste desafio foi disponibilizado um texto sobre as Inteligências Musical e a Corporal-Cinestésica, com o título: "Inteligência Musical e Inteligência Corporal-Cinestésica: Fundamentos Teóricos Para Aplicação no Objeto de Aprendizagem IM (Inteligências Múltiplas)”. Neste texto estão incluídos conceitos e informações sobre os Parâmetros Sonoros. Após a realização deste desafio, os alunos deveriam postar no ambiente quais parâmetros sonoros foram modificados e como foi sua experiência sonora.

No desafio 2 (Figura 4) foi disponibilizado uma Trilha Sonora chamada "Interações" em forma de canção, cuja letra foi criada pelas desenvolvedoras do OA e a música foi composta pela desenvolvedora Fátima Weber Rosas. Esta canção foi disponibilizada em duas versões: uma completa e uma versão incompleta. As duas versões foram disponibilizadas em formato mp3 e em arquivos do Word contendo a letra. Após escutar a versão incompleta os alunos deveriam compor um final para a 
mesma. A segunda versão, a completa ou original, possibilitou aos alunos compararem esta versão com as suas. Após a realização deste desafio, todos deveriam postar no ambiente utilizado suas reflexões após a comparação das duas versões.

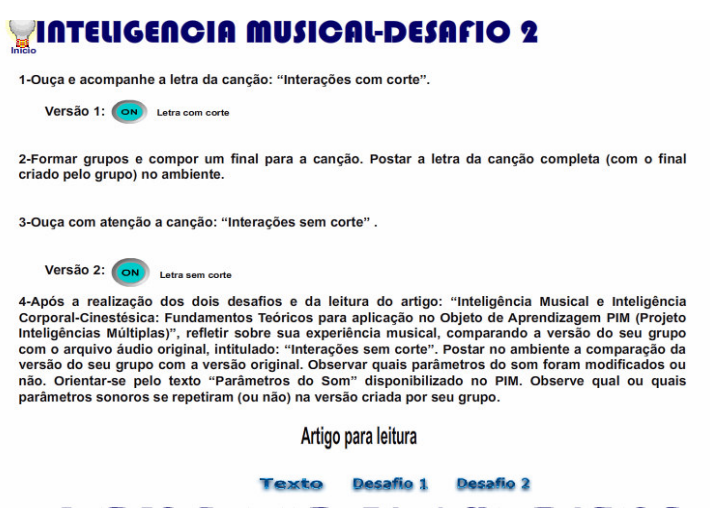

Figura 4 - Desafio 2 da Inteligência Musical

No recurso pedagógico "Inteligência Lógico Matemática”, assim como nas demais inteligências, existe um texto de apoio referente à inteligência e os desafios propostos foram a realização de um jogo, disponível em um site da internet, que utiliza o raciocínio lógico onde o usuário deveria criar estratégias para resolver o que foi proposto. Já no desafio 2, foram propostos dois problemas que utilizaram também de lógica para a resolução.

No recurso "Inteligência Corporal-Cinestésica", após a leitura do texto de apoio: Inteligência Musical e Inteligência Corporal-Cinestésica: Fundamentos Teóricos para Aplicação no Objeto de Aprendizagem IM Inteligências Múltiplas)”, foram realizados dois desafios. O primeiro desafio (Figura 5) consiste em assistir três vídeos contendo diferentes percussões corporais acompanhando a Trilha Sonora "Interações", criada pelas desenvolvedoras do objeto. Após assistirem os vídeos, os alunos deveriam escolher dois deles (duas percussões corporais) e realizá-las junto com os vídeos. Em seguida deveriam postar no ambiente, relatando como foi a sua experiência cinestésica. O segundo desafio consistiu na criação de uma percussão corporal para uma canção de livre escolha, seguido de registro contendo o nome da canção escolhida e um breve relato da percussão criada e de como foi sua experiência cinestésica. Nos vídeos a Trilha "Interações" foi apresentada completa e sem texto, ou seja, somente em sua versão instrumental.

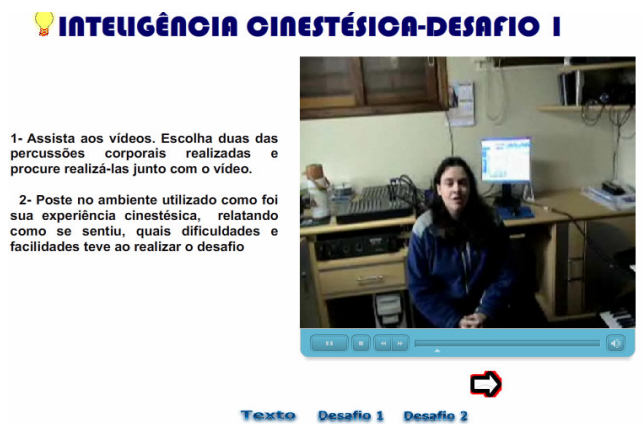

Figura 5 - Desafio 1 da Inteligência Corporal-Cinestésica 
No recurso "Inteligência Linguística", após a leitura do texto teórico, os desafios que foram propostos nesta inteligência visam mostrar o quanto o ser humano é dependente da linguagem. Pois não importa o formato que um texto se apresente a ele, este sempre vai ser seduzido pela linguagem do mesmo. Seja ele em formato de poesia ou narração. E o quanto é importante que a clareza se faça presente em sua comunicação, pois uma fala truncada, ou mal pontuada traz variadas interpretações (Figura 6). Para isso, foi proposto um enunciado com três elementos que poderiam ter diferentes funções, dependendo da pontuação da frase.

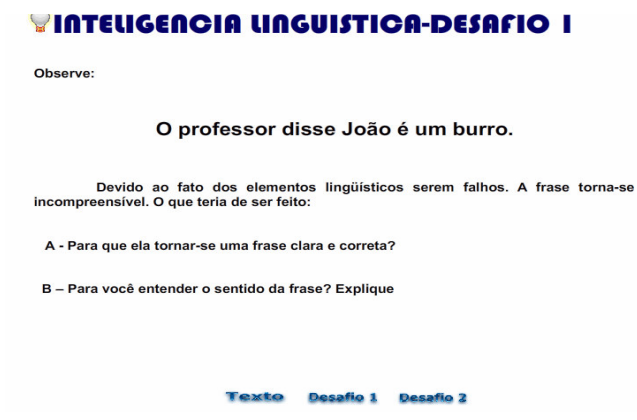

Figura 6 - Desafio 1 da Inteligência Linguistica

Recurso pedagógico “Inteligências Pessoais": Reflexivo ou extrovertido? Assim as inteligências pessoais mostram o ser humano, este pode ser voltado para si mesmo, ou aberto as coisas do mundo, e os desafios propostos visaram objetivar isto. $\mathrm{O}$ usuário do OA nestas inteligências tem a oportunidade de conhecer-se um pouco mais, aprendendo com os desafios a reconhecer qual delas é a que predomina em si. Ou se é possuidor das duas, pois nada impede que as inteligências interpessoal e intrapessoal componham uma mesma personalidade. Para tanto, foi pedido que eles ouvissem músicas. Cada uma delas traz presente emoções, que deveriam ser reconhecidas pelo ouvinte. Umas reflexivas, para aflorar a Inteligência Intrapessoal. Outra permitindo sociabilizar, através da Inteligência Interpessoal. (Figura 7).

\section{InTEUGÊnOIAS PESSOAIS-DESACIO I}

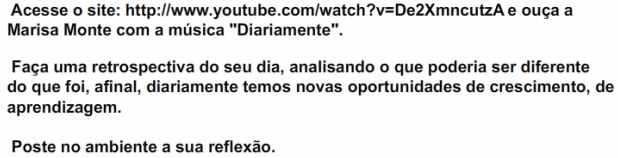

Poste no ambiente a sua reflexão.

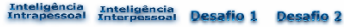

Figura 7 - Desafio 1 das Inteligências Pessoais

\section{CONSIDERAÇÕES FINAIS}

A construção desse objeto teve como foco a importância de como o educador pode desenvolver as inteligências múltiplas em seus educandos. Apesar do OA IM ter sido planejado e construído no intuito de abordar aspectos voltados para a virtualidade 
também poderá ser utilizado presencialmente. Pretendeu-se com ele proporcionar ao educador embasamento para o reconhecimento de qual inteligência seu educando possui, e possa utilizá-la como recurso de apoio para explanação ou fixação de seu conteúdo.

O OA IM foi aplicado na disciplina Oficinas Virtual de Aprendizagem, no Programa de Pós-Graduação da UFRGS (PGIE e PPGEDU), com duração de 20h, distribuída em quatro encontros. Ao final dos encontros foi aplicado um questionário para avaliação pedagógica e de interface. O objeto foi aprimorado após a aplicação e encontra-se cadastrado no CESTA ${ }^{4}$ para que possa ser reutilizado em outros contextos. De acordo com Behar (2009) os OAs nesses repositórios também podem ser utilizados como fonte de pesquisa e referência para que outros educadores o utilizem e avaliem.

O Ambiente Virtual de Aprendizagem (AVA) ROODA foi utilizado para as interações, bem como para as discussões e postagens dos exercícios disponibilizados no OA IM. Após seu uso na disciplina, realizou-se uma análise das interações dos alunos, chegando-se, num primeiro momento, a resultados parciais. De uma maneira geral, a turma mostrou-se favorável quanto à aplicação da Teoria das Inteligências Múltiplas a partir de um OA. Uma aluna registrou em um dos chats: "As TIC's podem possibilitar mais facilmente o desenvolvimento das Inteligências em função dos recursos que as mesmas oferecem" Outra aluna afirmou: "Obtive mais qualidade no desempenho dos meus alunos quando entendi que poderia obter mais resultados se motivasse sua atenção através do que eles se predispõem mais". Estes comentários mostram o quanto o objeto de aprendizagem IM possibilitou a reflexão sobre a Teoria trabalhada.

Alguns alunos se identificaram mais com algumas inteligências do que com outras. Quanto aos desafios, foram inúmeros os comentários. Relataram enfrentar diferentes graus de dificuldades na realização dos mesmos. Alguns chegaram a constatar que não tinham determinada habilidade relacionada a uma inteligência específica por nunca terem sido estimulados anteriormente.

Para utilizar o OA IM como recurso facilitador do processo de aprendizagem tanto no presencial como no virtual, o professor precisa conhecer a Teoria das Inteligências para uma aplicação adequada dos desafios propostos, identificando e motivando o desenvolvimento das inteligências em seus alunos. Para a utilização do OA IM em EAD, é importante o mesmo estar integrado a um AVA, para utilização dos recursos de interação e comunicação.

\section{NOTAS DE TEXTO}

${ }^{1-}$ Oficinas Virtuais de Aprendizagem - Disciplina oferecida pelo curso de Pós-Graduação em Educação e Informática na Educação/UFRGS, ministrada pela doutora Patrícia Alejandra Behar.

${ }^{2-}$ Fátima Weber Rosas. Graduada em Licenciatura em Música. UFRGS. Especialista em Artes e Educação Física na Educação Básica/UFRGS.

Letícia Rocha Machado. UFRGS/Pós-Graduação em Informática na Educação. Doutoranda em Informática na Educação/UFRGS.

Rissem HWAS. UFRGS/ Formação em Letras Pós-Graduação em Língua Portuguesa.

Terezinha TORRES. UFRGS. Mestra em Matemática

3- CmapTools é uma ferramenta que possibilita a criação colaborativa on-line de mapas conceituais de maneira síncrona. Este software permite que as palavras, conceitos, imagens e outros sejam interligados através de linhas conectoras.

4- CESTA (Coletânea de Entidades de Suporte ao uso de Tecnologia na Aprendizagem) é um serviço de diretórios que funciona como um repositório, permitindo o registro e a catalogação de objetos educacionais. 


\section{REFERÊNCIAS BIBLIOGRÁFICAS}

AMANTE, L; MORGADO, L. Metodologia de concepção e desenvolvimento de aplicações educativas: o caso dos materiais hipermedia. In: Discursos, III Série, $\mathrm{n}^{\circ}$ especial, p.125-138, Universidade Aberta, 2001.

ANTUNES, C. Inteligências Múltiplas e seus jogos.Vol.4 - Inteligência Espacial. Petrópolis: Vozes, 2006.

ANTUNES, C. Jogos para estimulação das Múltiplas Inteligências. Petrópolis, RJ Editora Vozes, 1998.

BARONE, D.A.C. \& SILVEIRA, S.R. Ciência Cognitiva e Inteligências Múltiplas: Teoria e Prática, v.4, nº1, p. 09-19, maio 2001. BEHAR, P (Col). Modelos Pedagógicos em Educação a Distância. Ed. Artmed, Porto Alegre, 2009.

BEYER, E. (Org.); LAZZARIN, L.F.; LEMOS LINO, D.; STAHLSCHMIDT, A.P. Idéias em Educação Musical - Cadernos de Autoria. $1^{a}$ ed. Porto Alegre: Mediação, 1999, 100p.

COSTA, J.S; MEDINA, R.D e BARONE, D.A.C. A Inteligência Corporal Cinestésica: O Movimento Inteligente. Informática na Educação: Teoria e Prática, v.4, nº 1, p. 63 68, maio 2001.

GARDNER, H. Inteligência: um conceito reformulado. São Paulo: Objetiva, 2000. Estruturas da mente: a teoria das inteligências múltiplas. Porto Alegre: Artmed, 2002.

Inteligência : múltiplas perspectivas. Porto Alegre: ArtMed, 1998. 1995. .Inteligências Múltiplas: A teoria na prática. Porto Alegre: Artes Médicas,

GASPARIAN, M.C. A psicopedagogia e as questões interdisciplinaridade e transdisciplinaridade. Revista da Associação Brasileira de Psicopedagogia. São Paulo, nº72, p.260-268, 1991.

LÉVY, P. A Máquina Universo. Instituto Piaget. 1987.

MACÊDO, L.N. et al. Desenvolvendo o pensamento proporcional com o uso de um objeto de aprendizagem. In: PRATA , Carmem Lúcia; NASCIMENTO, A.C.A.A. (Orgs).Objetos de aprendizagem: uma proposta de recurso pedagógico. Brasília: MEC/SEED, 2007.

MARTIN, R. Para entender a lingüística: epistemologia elementar de uma disciplina. São Paulo: Parábola Editorial, 2003.

NOVAK, J.D; CAÑAS, A. J. The Theory Underlying Concept Maps and How to Construct and Use Them. Disponível em:

$<$ http://cmap.ihmc.us/Publications/ResearchPapers/TheoryCmaps/TheoryUnderlyingCo nceptMaps.htm>. Acesso em: 27 de maio de 2009.

ROCHA, K.M; DUSO, L.M e BARONE, D.A.C. Inteligência Musical. Informática na Educação: Teoria e Prática, v.4, nº1, p. 45-51, maio 2001.

SILVA, M. Educação na cibercultura: o desafio comunicacional do professor presencial e on-line. Revista da FAEEBA - Educação e Contemporaneidade, Salvador, v. 12, n. 20, p. 261-271, jul./dez. 2003.

WILEY, D. Connecting learning objects to instructional design theory:A definition, a metaphor, and a taxonomy. 2000. In: WILEY, D.A (ed.), Instructional Use of Learning Objects. Association of Educational Communications and Technology. Disponível em: <http://wesrac.usc.edu/wired/bldg-7_file/wiley.pdf>. Acesso em: 04 de maio de 2009. 